\title{
Evaluation of trace elements and particulate matter deposition on plant foliage exposed to vehicular pollution
}

\author{
Aasawari A. Tak, Umesh B. Kakde* \\ Department of Botany, The Institute of Science, 15-Madame Cama Road, Fort, Mumbai - 400032, Maharashtra, India
}

\begin{abstract}
In recent times, highly developed metropolitan cities have progressively used biodiverse roadside plants as an eco-sustainable tool for the mitigation of air pollution. The present study has been designed to scrutinize the impact of particulate matter (PM) deposition and heavy metal accumulation in roadside plants. Some of the common roadside plants found along the national highway at Thane (Mumbai) region that were selected for this study are Alstonia schlolaris, Bauhinia variegata, Ficus benghalensis, Ficus religiosa, Cassia fistula, and Mangifera indica. The inductively coupled plasma atomic emission spectroscopy (ICP-AES) analysis was carried out for five heavy metals, namely $\mathrm{Cr}, \mathrm{Cu}, \mathrm{Fe}, \mathrm{Mn}$ and $\mathrm{Zn}$. The particulate matter deposition was observed to be the highest in Ficus benghalensis $\left(1.14 \mathrm{mg} \mathrm{kg}^{-1}\right)$, while it was found to be the lowest in Bauhinia variegata $\left(0.71 \mathrm{mg} \mathrm{kg}^{-1}\right)$. The present study revealed that the accumulation of heavy metals in plants inversely varies with the deposition of dust on the surface of leaves. The tolerant species of plants can serve as natural biofilters that can alleviate environmental pollution to certain extent.
\end{abstract}

Keywords: heavy metal, inductively coupled plasma atomic emission spectroscopy analysis, national highway, particulate matter, road traffic

\section{Introduction}

The plant physiology, anatomy, and its biochemical constituents are significantly influenced by specific climatic factors and certain air pollutants. It is a well-known and wellestablished fact that biodiversity in metropolitan cities is considerably affected by modern civilization, industrialization, economic growth, and urbanization. One such example is the city of Thane that has been known for its ecologically sensitive and rich flora and fauna; however, the severe stress of air pollution has brought the city on the verge of an environmental disaster. Green plants function as natural filters for air pollution as they continuously accumulate and absorb pollutants from the air. The plants that exhibit high tolerance towards air pollution are generally recommended for green belt development in urban and industrial areas (Tak and Kakde 2017a).

Heavy metals are stable elements (Tokalioglu and Kartal 2006) that cannot be destroyed or degraded, and are known as the essential natural elements of the Earth's crust. These elements enter into the environment due to several anthropogenic activities such as agriculture, industrial processes, energy production, and burning of fossil fuel. In urban green forests, these metals are released into the environment in the form of air particulates that scatter in solid or liquid states, with sizes of about $1 \mu \mathrm{m}$ (Sawidis et al. 2011). Vehicular emissions in urban regions are considered to be the primary source of pollution caused by these elements (Duong and Lee 2011). Some of the other anthropogenic sources of heavy metals include traffic, mining processes, combustion of petrochemical byproducts, diffuse and smelter sources (piping), human activities, and industrial sources (Al-Khashman et al. 2011). It was recorded by Thorpe and Harrison (2008), the high emission rate of automobile exhaust affects the roadside plants. Friction of brake linings and tires and corrosion and erosion of vehicular metal parts over time contribute to the emission of various heavy metal pollutants onto the roadside environment. Brake linings are generally made up of iron $(\mathrm{Fe})$ and copper $(\mathrm{Cu})$. The application of brakes results in the release of iron and copper due to frictional heat (Luhana et al. 2004). Iron is also used in the construction of roads, bridges, and welding work, and corrosion of iron parts over time leads to release of iron in the environment. During the manufacturing of rubber, zinc is used as an important additive 
for vulcanization of rubber. Hence, erosion and corrosion of tires leads to release of $\mathrm{Zn}$, (Hjortenkrans et al. 2007). Therefore, the present study is based on analyzing the accumulation of five heavy metals, namely $\mathrm{Cr}, \mathrm{Cu}, \mathrm{Fe}, \mathrm{Mn}$, and $\mathrm{Zn}$ on plant foliages, and considers the amount of dust deposition.

Dust or particulate matter and gaseous pollutants can have adverse effects on plants as well as human health (Raabe 1999, Rai et al. 2013). Since, the leaves of plants are sensitive; they show visible damages on their surfaces during the overall developmental stages when exposed to these pollutants (Steubing et al. 1989). Some of the most common and high severity air pollutants include $\mathrm{SO}_{2}, \mathrm{NO}_{2}$, and $\mathrm{CO}_{2}$. These air pollutants also leave a negative impact on the morphology, physiology, and biochemistry of plants. At the same time, the use of tolerant plant species to mitigate air pollution is widely accepted. By assessing the morphological, physiological, and biochemical parameters of plants, an early evaluation of urban air quality can be arrived at. Several studies were carried out to analyze and understand the impacts of air pollution on selected plants in polluted urban regions (Tak and Kakde 2017b).

On the other hand, no systematic analysis has been performed in an urban section of an ecologically sensitive region such as Thane, India. In addition to this, a plant's response may alter under varying levels of pollution stress (Tak and Kakde 2017b). Plants are usually readily available and can be modified more easily compared to other organisms such as fungi, algae, lichens, or mosses (Berlizov et al. 2007).

In the light of the above-mentioned discussion, the present study deals with the quantification of dust particles and accumulation of heavy metals on the leaves of different roadside plant species in the Thane (Mumbai) region.

\section{Material and methods}

\section{Study area}

National highway 48 (NH 48) is a national highway of India that starts at Delhi and ends at Chennai and goes through Jaipur, Udaipur, Vadodara, Mumbai, Pune, and Bengaluru, traversing through six states of India. The present investigation was carried out at National Highway 48 from Teen Haat Naka (Co-ordinates $19^{\circ} 11^{\prime} 17.4192^{\prime \prime N} 72^{\circ} 57^{\prime} 49.9932^{\prime \prime E)}$ to Kasarvadavali (Co-ordinates $\left.19^{\circ} 16^{\prime} 14.1348^{\prime \prime} \mathrm{N} 72^{\circ} 57^{\prime} 53.604^{\prime \prime} \mathrm{E}\right)$ on Ghodbunder road, Thane, Maharashtra. The selected area is a high traffic area and the National Highway 48 passes through it. Thousands of vehicles such as cars, bikes, trucks, and tractors continuously pass through this area, which is a source of high level of heavy metals pollution. In addition, there is a greater intensity of dust accumulation on highway roads. Hence, the plant foliage along the highway was selected for the analysis of dust and heavy metals. The Yeoor hill forest (Co-ordinates $19^{\circ} 13^{\prime} 56.5464$ N 7256'48.066”E) was selected as non-polluted site (control).

\section{Sampling}

The plant species that were selected include Alstonia scholaris, Bauhinia variegata, Ficus benghalensis, Ficus religiosa, Cassia fistula, and Mangifera indica. These plants are commonly available and grow naturally. For the dust and heavy metal analysis, the leaf samples of these roadside plants were taken from the height of 2 to $3 \mathrm{~m}$ from ground level, where high amount of dust particles settle on the surface of foliage. The foliage facing towards roadside was collected for sampling early in the morning from 8.00 a.m. to 10.00 a.m. through random selection. Three replicates of leaf samples were put in separately labeled zip lock polythene bags. All the leaf samples were carefully transferred to laboratory for further analysis.

\section{Dust analysis}

The amount of dust deposited on the leaf surface area was calculated by taking the initial and final weight of beaker in which the leaf samples were washed. The following formula was used for the calculation: $\mathrm{W}=\mathrm{W} 2-\mathrm{W} 1 / \mathrm{A}$, where $\mathrm{W}=$ dust content $\left(\mathrm{mg} \mathrm{cm}^{-2}\right), \mathrm{W} 1=$ weight of beaker without dust, W2 = weight of beaker with dust and A = total area of leaf in $\mathrm{cm}^{2}$.

\section{Heavy metal analysis}

Inductively coupled plasma atomic emission spectroscopy (ICP-AES) was used for analyzing the presence of heavy metals, i.e., chromium, copper, iron, manganese, and zinc, which are commonly and abundantly found in the dust samples collected from the roadside foliage. Using the closedvessel microwave system and the wet method, the collected samples were processed in a fusion of nitric acid and hydrogen peroxide. A high performance microwave digestion system Multiwave 3000 (Anton Paar) was applied for microwave digestion of the samples. Perkin Elmer Elan DRC II inductively coupled plasma mass spectrometer was used for the determination of $\mathrm{Cr}, \mathrm{Cu}, \mathrm{Fe}, \mathrm{Mn}$ and $\mathrm{Zn}$. To begin with, $0.1 \mathrm{~g}$ (dry mass) of plant sample was weighed into the digestion vessels. Then, $5.0 \mathrm{~mL}$ of concentrated $\mathrm{HNO}_{3}$ and $1.0 \mathrm{~mL}$ of $30 \% \mathrm{H}_{2} \mathrm{O}_{2}$ were added to each sample. All the chemicals used for the digestion process were of analytical grade. The samples were then pre-digested overnight (for 16 hours) in a fume hood at room temperature. Since temperature control was required during the entire decomposition, a temperature sensor was used in one vessel. The plant samples were digested according to the specifications of the following optimized program (power in W/time in min): $1000 / 28$, ventilation for $20 \mathrm{~min}$. During the last step and ventilation, the internal temperature was limited to $240^{\circ} \mathrm{C}$. After cooling, the entire digest was transferred in portions into $60 \mathrm{~mL}$ plastic bottles and each bottle was diluted with $50 \mathrm{~mL}$ of double deionized water. Similarly, reagent blanks were prepared for the samples. The entire sample solution was clear and diluted 10 times before analysis. The ICP-AES system was calibrated by the method that involved external standards with $\mathrm{Rh}$, and internal standards with Re. The reagent blank solution contained $1 \%$ of concentrated $\mathrm{HNO}_{3}$. Using the reagent blank solutions, a mixed standard solution was prepared that contained all five elements, i.e., $\mathrm{Cr}, \mathrm{Cu}, \mathrm{Fe}$, 
$\mathrm{Mn}$ and $\mathrm{Zn}$. The background interferences from the plasma gases, air entrainment, and solvent were corrected by subtraction of signals from reagent blank solutions.

\section{Statistical analysis}

The correlation coefficient between dependent and independent variables was calculated using the Analysis ToolPack in Excel. The degree of correlation was determined by the Pearson correlation coefficient. In the present investigation, the independent variable was dust deposition and the dependent variables were heavy metals. For all primary data, $\mathrm{n}=12$, and significance was tested at a $5 \%$ level (that is, $p<0.05$ ). Data interpretation was executed by one-way ANOVA, followed by the Tukey Kramer test to check the significance of dust accumulation and heavy metal absorption by plant leaves for selected study sites at $(\mathrm{p}<0.05)$.

\section{Results and discussion}

\section{Accumulation of heavy metals}

The heavy metals released from vehicular emissions directly get deposited in soil, and are thus translocated in plants via the root system (Shparyk and Parpan 1990). Accumulation of selected heavy metals at control and polluted sites has been depicted in Figure 1. The elements with metallic properties and atomic number more than 20 are usually referred to as heavy metals. Heavy metal pollution is a significant environmental issue as these metals are likely to have toxic effects with increased concentration or accumulation in plants. The accumulation of heavy metals in plants leads to physiological toxicity in plants, animals, and microorganisms. Due to the accumulation of heavy metals, the leaves may get damaged and cause serious ecological and health problems if the heavy metals enter into the food chain. Heavy metal pollution does not undergo biodegradation and has a harmful effect on biological systems.

In the present investigation, accumulation of chromium (Cr; Fig. 1A) was recorded to be maximum in Cassia fistula (16.4 $\left.\mathrm{mg} \mathrm{kg}^{-1}\right)$ and Bahunia variegata $\left(11.1 \mathrm{mg} \mathrm{kg}^{-1}\right)$, while the minimum accumulation of this metal was recorded in $\mathrm{Fi}$ cus religiosa and Ficus benghalensis ( $\left.1.0 \mathrm{mg} \mathrm{kg}^{-1}\right)$. According to Pais and Jones (1997), $\mathrm{Cr}$ contents in plants ranges from $0.02-0.2 \mathrm{mg} \mathrm{kg}^{-1}$ with phytotoxicity at $>10 \mathrm{mg} \mathrm{kg}^{-1}$. Cr content in air ranges from $0.001-1.0 \mathrm{mg} \mathrm{m}^{-3}$, but in industrial regions, it reaches up to $30-50 \mathrm{mg} \mathrm{m}^{-3}$. In this investigation, the concentration of $\mathrm{Cr}$ was recorded to be higher in plants than the values recorded when the plants are under normal conditions. The presence of $\mathrm{Cr}$ in polluted areas is found to be toxic for the growth of plants. Higher concentration of $\mathrm{Cr}$ in plants results into chlorosis of foliage, necrotic spots, and injured rot growth (Kabata-Peadias et al. 1994).

The accumulation of $\mathrm{Cu}$ was recorded to be the highest in Bahunia variegata (39.6 $\mathrm{mg} \mathrm{kg}^{-1}$ ) while it was found to be the lowest in Ficus religiosa $\left(10.8 \mathrm{mg} \mathrm{kg}^{-1}\right)$. The normal range of $\mathrm{Cu}$ in plant leaves is from $3-7 \mathrm{mg} \mathrm{kg}^{-1}$ of the dry matter, while toxicity is in the range of $20-30 \mathrm{mg} \mathrm{kg}^{-1}$
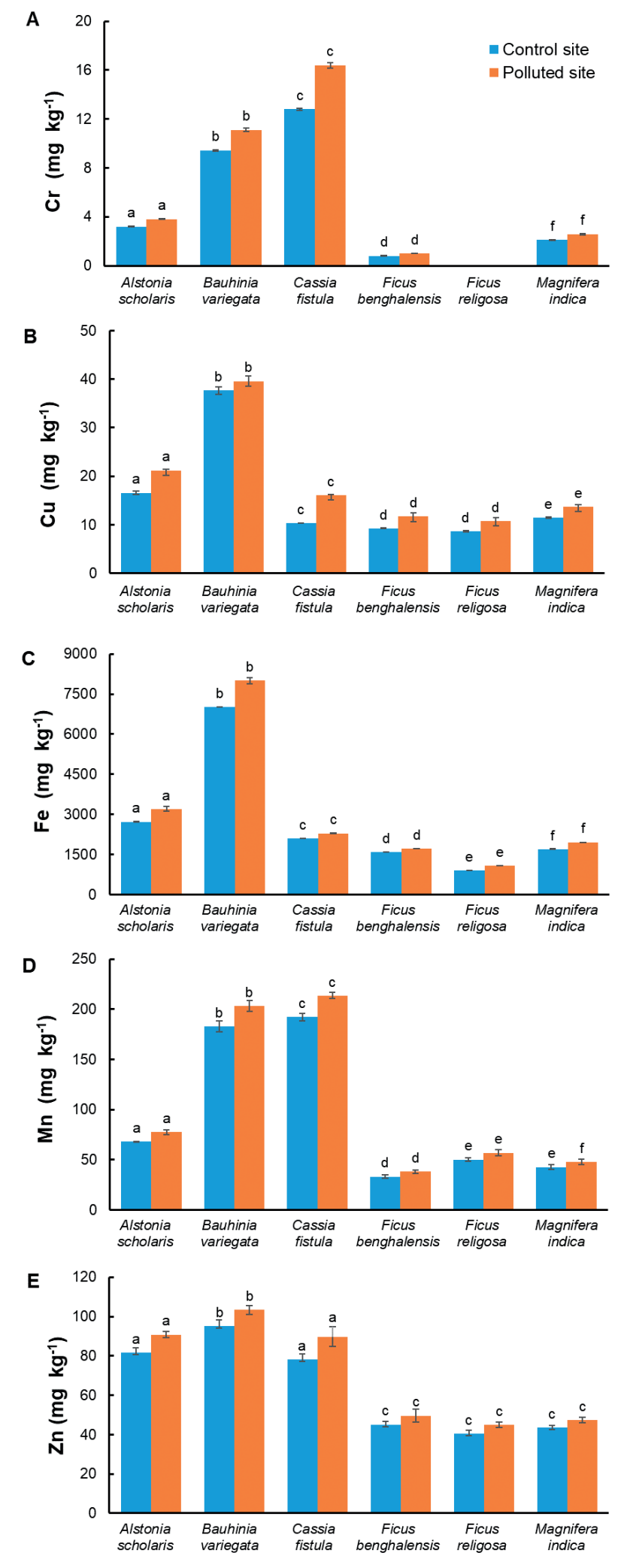

Fig. 1. Accumulation of heavy metals in leaves of Alstonia scholaris, Bauhinia variegata, Ficus benghalensis, Ficus religiosa, Cassia fistula, and Mangifera indica at control and polluted sites. A - accumulation of chromium $(\mathrm{Cr}), \mathrm{B}-$ accumulation of copper $(\mathrm{Cu}), \mathrm{C}-\mathrm{ac}-$ cumulation of iron (Fe), D - accumulation of manganese (Mn), E - accumulation of zinc (Zn). Data are mean values $(n=3)$, the error bars indicate standard deviations. Different letters denote statistically different means according to the Tukey Kramer post ad-hoc test $(\mathrm{p}<0.05)$. Control plants were collected from the Yeoor hill forest (non polluted area). 
(Kabata-Peadias and Pendias 1994). It is observed that the concentration of $\mathrm{Cu}$ in the leaf samples was higher than the normal limits.

The accumulation of iron $(\mathrm{Fe})$ was recorded to be the highest in Bahunia variegata $\left(7.963 \mathrm{mg} \mathrm{kg}^{-1}\right.$ ), while it was recorded to be the lowest in Ficus religiosa $\left(1.081 \mathrm{mg} \mathrm{kg}^{-1}\right)$. The Fe content in plants ranges from $10-1000 \mathrm{mg} \mathrm{kg}^{-1}$ in dry matter. Fe is the most important element in protein constituent of plants, which helps in $\mathrm{N}_{2}$ fixation, and is also known as a catalyst in chlorophyll formation Caselles et al. (2002).

The maximum accumulation of manganese (Mn) was recorded in Cassia fistula $\left(213.6 \mathrm{mg} \mathrm{kg}^{-1}\right)$, while the lowest was in Ficus benghalensis ( $38.3 \mathrm{mg} \mathrm{kg}^{-1}$ ) (Figure 1). An excess accumulation of Mn by plants leads to older leaves with brown spots (Horiguchi 1987). In this analysis, the Mn concentration was found to be below the range of toxicity.

The accumulation of Zinc ( $\mathrm{Zn}$ ) was recorded to be the highest in Bahunia variegata (103.4 $\mathrm{mg} \mathrm{kg}^{-1}$ ), while it was the lowest in Ficus religiosa $\left(45.0 \mathrm{mg} \mathrm{kg}^{-1}\right)$. High accumulation of $\mathrm{Zn}$ in plants results in older leaves as it has high bioaccumulation index (Aleksandra et al. 2017).

\section{Accumulation of dust by plants}

The accumulation of dust deposition was found to be the highest in Ficus benghalensis (1.14 $\mathrm{mg} \mathrm{kg}^{-1}$ ), while it was the lowest in Bauhunia variegata $\left(0.71 \mathrm{mg} \mathrm{kg}^{-1}\right)$. An analysis of dust accumulation indicated insignificant correlation with the deposition of toxic heavy metals such as $\mathrm{Cr}, \mathrm{Cu}$, $\mathrm{Fe}, \mathrm{Mn}$, and $\mathrm{Zn}$ at the polluted site. A decreasing sequence of heavy metal contamination in plant foliage was recorded as follows:

Ficus benghalensis $>$ Mangifera indica $>$ Cassia fistula $>$ Alstonia scholaris $>$ Bauhunia variegata $>$ Ficus religiosa.

Figure 2 depicts the dust deposition pattern on foliage of selected plants. To analyze the correlation between accumulated heavy metals and dust, a correlation matrix was plotted and is presented in Tab. 1. A significant positive correlation was observed between $\mathrm{Mn}-\mathrm{Cr}$ (0.961), Cu-Fe (0.995), and $\mathrm{Zn}-\mathrm{Mn}$ (0.822). Correlation between $\mathrm{Cu}-\mathrm{Cr}, \mathrm{Fe}-\mathrm{Cr}$ and $\mathrm{Fe}-\mathrm{Mn}$ was not significant, but it was found to be positive. All selected heavy metals and dust were observed to be negatively correlated. One-way ANOVA test for heavy metals and dust revealed that all the heavy metals were significant among control and experimental sites.

The accumulation or absorption of dust depends on the surface geometry, external climatic changes, phyllotaxy, leaf area, hairs, cuticle, height, and canopy structure of plant species. Plants with broad leaf area and wide branches tend to absorb more dust. The parameters such as height and phyllotaxy of leaf surfaces are considered to cause a reduction in the particulate matter or dust deposition on leaf surfaces (Thambavani and Sabitha 2011). The effect on dust deposition and heavy metals accumulation in plants foliage in the present investigation due to these parameters was observed to be insignificant.
Tab. 1. Pearson correlation of accumulated heavy metal concentration (chromium, copper, iron, manganese and zinc) and dust in leaves of different roadside plant species (Ficus benghalensis, Mangifera indica, Cassia fistula, Alstonia scholaris, Bauhunia variegata, and Ficus religiosa). Significance was tested for $\mathrm{p}<0.05$ and significance values were highlighted by ${ }^{*}$. Positive values in the matrix indicate positively correlated, while negative (-) values indicate inversely correlated results.

\begin{tabular}{ccccccc}
\hline & Dust & $\mathrm{Cr}$ & $\mathrm{Cu}$ & $\mathrm{Fe}$ & $\mathrm{Mn}$ & $\mathrm{Zn}$ \\
\hline Dust & 1.000 & & & & & \\
$\mathrm{Cr}$ & -0.357 & 1.000 & & & & \\
$\mathrm{Cu}$ & -0.645 & 0.493 & 1.000 & & & \\
$\mathrm{Fe}$ & -0.592 & 0.477 & $0.995^{\star}$ & 1.000 & & \\
$\mathrm{Mn}$ & -0.564 & $0.961^{*}$ & 0.652 & 0.637 & 1.000 & \\
$\mathrm{Zn}$ & -0.619 & 0.770 & 0.805 & 0.764 & $0.822^{\star}$ & 1.000 \\
\hline
\end{tabular}

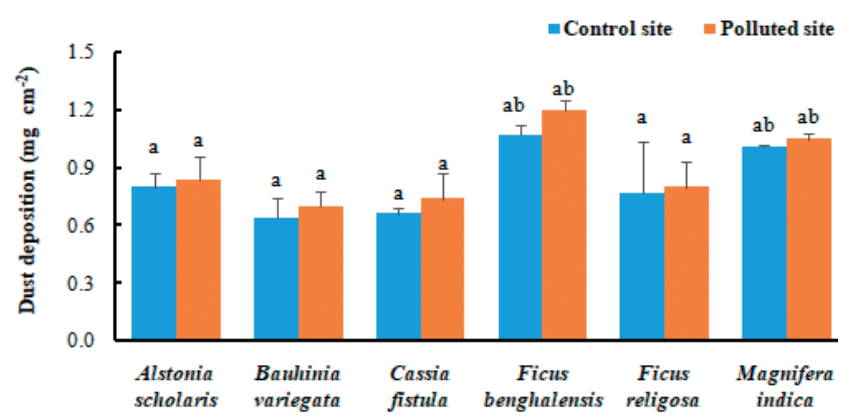

Fig. 2. Dust deposition on foliage of Alstonia scholaris, Bauhinia variegata, Ficus benghalensis, Ficus religiosa, Cassia fistula and Mangifera indica. Control plants were collected from the Yeoor hill forest (non polluted area). Data are mean values $(n=3)$. The error bars indicate standard deviations. Error bars with different alphabets have statistically different mean inter specific as per the Tukey Kramer post ad-hoc test $(\mathrm{p}<0.05)$.

\section{Conclusion}

From the present study, some useful observations were made regarding the dust absorbing capacity and the extent of heavy metal accumulation of different plants. The vehicular emission, known to be hazardous to human health, is found to negatively impact the life cycle of plants as well. As the heavy metals are released in soil and in air, plants accumulate and absorb these into their system either by root translocation system or through photosynthesis and respiration.It was observed that plants, namely Ficus benghalensis, Mangifera indica, Cassia fistula, Alstonia scholaris, Bauhunia variegata, and Ficus religiosa, have considerable tolerance toward pollutants as they accumulated some high toxic metals in their system. These plants are suggested to be planted along roadside where vehicular emission is more. As plants function as biofilters of air pollution, they also accumulate some toxic metals into their root system, making the soil less toxic. To sum up, urban roadside plantation can serve as biomarkers or natural biofilters of air pollution for the development of greenbelts. 


\section{References}

Aleksandra, N.S., Marta, K.C., Michał, T., Gabriela, B., 2017: Air pollution tolerance index and heavy metal bioaccumulation in selected plant species from urban biotopes. Chemosphere 183, 471-482.

Al-Khashman, O.A., Al-Muhtaseb, A.H., Ibrahim, K.A., 2011: Date palm (Phoenix dactylifera L.) leaves as biomonitors of atmospheric metal pollution in arid and semi-arid environments. Environmental Pollution 159, 1635-1640.

Berlizov, A.N., Blum, O.B., Filby, R.H., Malyuk, I.A.,Tryshyn, V.V., 2007: Testing applicability of black poplar (Populusnigra L.) bark to heavy metal air pollution monitoring in urban and industrial regions. Science of the Total Environment 372, 693-706.

Caselles, J., Colliga, C., Zornoza, P., 2002: Evaluation of trace elements pollution from Vehicle emissions in Petunia plants. Water Air and Soil Pollution 136, 1-9.

Duong, T.T.T., Lee, B.K., 2011: Determining contamination level of heavy metals in road dust from busy traffic areas with different characteristics. Journal of Environmental Management 92, 554-562.

Hjortenkrans, D.S.T., Bergback, B.G., Haggerud, A.V., 2007: Metal emissions from brake linings and tires: case studies of Stockholm, Sweden 1995/1998 and 2005. Environmental Science and Technology 41, 5224-5230.

Horiguchi, T., 1987: Mechanism of manganese toxicity and tolerance of plants. Soil Science and Plant Nutrition 33, 595-606.

Kabata-Pendias, A., Pendias, H., 1994: Trace elements in soil and plants, $2^{\text {nd }}$ edition. CRCPress, Boca Raton, Florida.

Luhana, L., Sokhi, R., Warner, L., Mao, H., Boulter, P., McCrae, I., Wright, J., Osborn, D., 2004: Characterization of exhaust particulate emissions from road vehicles (Particulates); FP5 particulates project.

Pais, I., Benton, J.J., 1997: The handbook of the trace elements. St. Lucie press, Boca Raton, Florida.
Raabe, O.G., 1999: Respiratory exposure to air pollutants. In: Swift, D.L., Foster, W.M. (eds), Air pollutants and the respiratory tract, 39-73. Marcel Dekker Inc, New York.

Rai, P.K., 2013: Environmental magnetic studies of particulates with special reference to bio magnetic monitoring using roadside plant leaves. Atmospheric Environment 72, 113-129.

Sawidis, T., Breuste, J., Mitrovicc, M., Pavlovic, P., Tsigaridas, K., 2011: Trees as bioindicators of heavy metal pollution in three European cities. Environmental Pollution 159, 3560-3570.

Shparyk, Y.S., Parpan, V.I., 1990: Heavy metal pollution and forest health in Ukrainian Carpathians. Environmental Pollution 130, 55-63.

Steubing, L., Fangmeier, A., Both, R., 1989: Effects of $\mathrm{SO}_{2}, \mathrm{NO}_{2}$ and $\mathrm{O}_{3}$ on pollution development and morphological and physiological parameters of native her layer species in a beech forest. Environmental Pollution 58, 281-302.

Tak, A.A., Kakde, U.B., 2017a: Assessment of air pollution tolerance index of plants: a comparative study. International Journal of Pharmacy and Pharmaceutical Sciences 9, 83-89.

Tak, A.A., Kakde, U.B., 2017b: Comparative study of air pollution tolerance and performance index of some plants growing in an industrial area. Online International Interdisciplinary Research Journal 7, 23-31.

Thambavani, S.D., Sabitha, M.A., 2011: Variation in air pollution tolerance index and anticipated performance index of plants near a sugar factory: implications for landscape-plant species selection for industrial areas. Journal of Research in Biology 1, 494-502.

Thorpe, A., Harrison, R.M., 2008: Sources and properties of nonexhaust particulate matter from road traffic: a review. Science of the Total Environment 400, 270-282.

Tokalioglu, S., Kartal, S., 2006: Multivariate analysis of the data and speciation of heavy metals in street dust samples from the organized industrial district in Kayseri (Turkey). Atmospheric Environment 40, 2797-2805. 